\title{
Blended Learning and Its Applications in English Writing for Chinese Students
}

\author{
Weizhong Rao \\ Foreign Languages Department \\ Fujian Commercial College \\ Fuzhou, China
}

\begin{abstract}
The paper aims to study blended learning and how it is applied in Chinese college English writing teaching. It also explores how blended learning is utilized to enhance the effectiveness of teaching writing, as well as the students' information literacy and critical thinking ability. The participants are 42 students of non-English major who were purposefully selected from one college in Fujian, China. The instruments for data collection were tests, classroom observation and structured interviews. The findings reveal the effectiveness and importance of blended learning strategy used in Chinese college English writing teaching as well as the students' writing proficiency.
\end{abstract}

Keywords-information technology; blended learning; writing proficiency

\section{INTRODUCTION}

The teaching of English involves four language skills (listening, speaking, reading and writing) which students should master to become proficient users of this target language. However, due to the characteristics of the writing course and the differences of culture thinking between the western and Chinese, the writing teaching is not satisfactory. In 2009, the United States Department of Education issued a report of An empirical study of online learning: Meta analysis and comment on online learning, which showed that blended learning is one of the most effective ways of learning.Thus, Blended learning has been paid more attention by many experts and scholars. This paper explores how the teacher makes WeChat, online writing and correcting software and classroom teaching blended into the English writing teaching, then, through classroom observation, interview and test data acquisition, to investigate students' attitudes towards the blended learning strategies on improving their writing skills.

\section{REVIEW OF LITERATURE}

A cursory look at the literature reveals that many scholars have defined blended learning differently. According to learning circuits of The United States, blended learning is considered to be a combination of online learning and classroom learning. Driscoll (2002) defines to blend learning as intermixing of any instructional forms to achieve an educational goal. Singh (2003) views blended learning as combining different delivery media to promote meaningful

This paper is the initial results of the youth teacher education research project of Fujian Province in 2016: Research on College English writing blended teaching model based on Information Technology (JZ60045) and motivating learning. In China, many scholars did a lot of studies on the learner's writing teaching, but most of them concerned about 'the students' peer feedback and the teacher's feedback(Cai, 2011; Li, 2015)', 'multi-role participation in writing teaching(Shao, 2016)', Zhu (2003) introduced blended learning for the first time in China in her book of Blended learning in Distance Education(Wang et al, 2015). He(2004) claims blended learning as a combination of the advantages of the traditional learning and e-learning; that is to say, in which not only the teacher plays a leading role of the guidance and inspiration, monitoring during the teaching process, but also the students can play their initiative, enthusiasm and creativity in the learning process. Only with the combination of the two parts can the best learning effectiveness be obtained. Han (2014) argues that blended teaching model can effectively improve the level of writing and promote the development of English Majors' speculative ability. Therefore, this current study is intended to investigate whether blended learning has a significant effect on ESP students'writing skills and explore their attitudes towards blended learning. The study tries to answer the research questions below:

- Does blended learning have an impact on the students' achievement in their overall writing ability?

- What are the students' attitudes towards blended learning strategy?

\section{METHODOLOGY}

\section{A. Participants}

The research was conducted with 42 Chinese students at a college in Fuzhou, Fujian. The students were freshmen of non-English major at the Department of Economic Trade at Fujian International \& Economic college. As this study was carried out in the second term, considering the students had already taken Integrated English course in which they had been taught the basics of writing, different methods of how to write business letters, a proficiency exam of arguemental writing was taken at the beginning of the second term, it was determined that the students were on the elementary Level.The study was supervised by the researcher himself. The participants' ages ranged from 18 and 20. At the time of data collection, they were all taking the writing course of Integrated English, in which they were instructed to write an argumentative essay. The whole writing teaching 
procedure ,as well as the interview, was traced, recorded and then transcribed into the text.

\section{B. Data collection instruments}

The first collection instrument was the students' in-class argumentative writing on the same topic according to the same requirement of 180 words, which were administered prior to and after the formal instruction (measured as pre-test, post-test). The overall writing performance and writing skills were measured by the writing scoring and correcting software developed by Beijing Word Network Technology Co., Ltd.. The participants' two argumentative essays (pretest, post-test) were scored by the writing-scoring and correction software and the results were averaged and compared. The last instrument was the student satisfaction interview conducted by the instructor in order to know the students' achievement in their overall writing ability and their attitudes towards blended learning and teaching.

\section{Procedure}

The experiment was carried out for three stages of before-class, in-class and after-class learning activities. Before the experiment, the pre-test (writing an argumentative essay on the topic of "My View On Reducing Carbon Emission" ) was taken on the internet and scored by by the writing-scoring and correction software. The test was to investigate the students' weaknesses and strengths about each aspect of their writing ability, such as organization, word accuracy and vocabulary and so on . At the beginning of the procedure, the students were divided into 7 groups, of which every group was a learning community. Meanwhile, Mobile QQ and WeChat groups were set up and the students were asked to join in them by the instructor, which were utilized to teach, learn and deliver writing materials.

\section{1) Before-class activity}

- Step One. Some pictures and videos were presented on the WeChat group, which were related to the writing topic of My View On Reducing Carbon Emission.Then the instructor, through audio teaching, asked the students what ideas would come into the mind map and let them brainstorm and present the words or phrases related to the topic. Five Minute later, words and phrases were shown on WeChat one by one as follows: environmental problem, global warming, climate changes, destroy the environment, damage people's health, make and implement relevant laws, use purification systems, take practical action, reducing the use of vehicles, etc.

- Step Two. Brief introduction of the argumentative writing. Instructor: Argumentative writing is a kind of composition that aims at convincing the reader. It tries to make the reader agree with its point of view and support it, to persuade him to change his mind or behavior. And its discourse structure is often presented as follows:

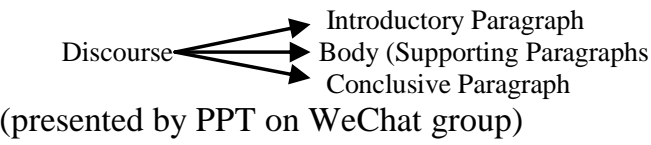

Instructor: As far as the introductory paragraph concerned, it is like a funnel. What is the shape of the funnel?

Students: The upper of the funnel is broader while the lower is narrower.

Instructor: Right. One common shape of the introduction paragragh development is the "funnel shape" as follows:

$$
\begin{gathered}
\text { A broad statement about your main idea } \\
\text { A more specific statement, Closer to main idea } \\
\text { A more specific statement, Even closer to your main idea } \\
\text { Your thesis statement } \\
\text { (presented by PPT on the WeChat group) }
\end{gathered}
$$

Instructor: Develop the topic sentence by some relevant supporting sentences as follows. We can give some examples, facts, figures etc. to be the supporting sentences. Understand?

Ss: Yes.

$$
\begin{gathered}
\text { Topic sentence } \\
\text { Supporting sentence1 } \\
\text { Supporting sentence2 } \\
\text { Supporting sentence3 } \\
\text { Supporting sentence4 } \\
\text { Concluding sentence }
\end{gathered}
$$

(presented by PPT on the WeChat group)

Instructor: In general, write the concluding part by giving a brief summary, to call for some sort of action, or to give warnings or suggestions to readers. Meanwhile, to make the sentences more coherent, we need to use some transitive words and phrases in every part as follows. Get it?

$$
\text { Ss: Yes }
$$

(1) at first, then, later, in the end, finally, at last...

(2) thanks to, due to, because of, as a result(of), therefore...

(3) but, yet, however, on the contrary, otherwise, in spite of...

(4) for example, take...as an example, in other words..

(4) what's more, besides, apart from, in addition to... (presented by PPT on the Wechat group)

\section{2) In-class activity}

After the writing topic was given to the students, they were required to list the writing outline, then had the online draft writing. During the writing process, the students were allowed to use the automatic correction function of Word program to find and correct spelling and grammar mistakes in the essays, then submitted the essays on the writing scoring and correcting software, the scores were presented on the website.The students had online self-assessment and peer assessment. Then, the learning community group were together to discuss the existing problems and what they had learned. Last, one chosen member of the learning community group made a writing summary and comment before the whole class. The instructor walked round the classroom and offtered assistance to them and did the final comments.

\section{3) After-class activity}

After class the instructor spared some time and continued to chat with the students through the WeChat group, tried to learn about their problems they met in their 
study. The instructor pointed out that what the students needed to improve and offered more assistance.

\section{DATA ANALYSIS AND DISCUSSION}

\section{A. Evaluation on the Procedures}

Before class, by viewing the pictures and brainstorming, the students had a better understanding of the theme with their previous knowledge, they could think of words, phrases of the theme and plan for their writing quickly. The instructor and the students had a good teaching interation via the internet, as 'Learning emerges as a result of various interactions that the individual gets into with the social environment s/he lives in and through the construction of knowledge on the mind (Vygotsky, 1978)', which could help the students have a general framework in mind and would do a lot of benefit for the in-class training activity.

The instructor and the students can break the limits of time and space for their teaching and learning through WeChat. That is, it is likely that the instructor and the students can instruct and learn at anytime and anywhere. In class, through the warm discussion and interaction, it can not only help the students understand and master the language knowledge, but also help them to have a critical thinking, then enhance the ability of their communication between the individual and the social members. After class, by communicating witih the students, which really let the students feel loved, the students would transfer their emotional power into their learning interests and motivation of writing happily.

\section{B. Comparison of the Pre-test and the Post-test}

TABLE I. The Average SCORE OF THE Two TESTS

\begin{tabular}{|c|c|c|}
\hline Test & Pre-test & Post-test \\
\hline Average & 61 & 80 \\
\hline
\end{tabular}

From "Table I", it can be seen that the average score of the pre-test was only 61 points while the average score of the post-test was 81 points, which was 19 points higher than that of the pre-test. And the results indicated that blended learning strategy applied in the English writing was effective.

\section{Interview}

For a further evaluation of the effectiveness of teaching and learning, the semi-structured interview was conducted by the instructor. A total of eight students were randomly selected with recording interviews, transcribed as follows:

"Blended writing teaching taught me to find useful information."

"With blended learning, I learned to find useful information in the vast ocean of information."

"Blended writing teaching could make me have accumulated a large number of vocabulary."

"The writing correcting software can modify the composition to my satisfaction, it is cool."

"Blended writing teaching could let us have the motivation to learn."

"I find that I am more confident than before and will write better."
"I hope I can write out a better essay next time, I believe I will."

"It was impossible for me to feel that I had written so many words in such a short period of time before."

From the interview, it can be seen that most of the students felt that blended teaching and learning was very useful in their writing, and welcomed than before. Motivation is an important factor that affects the success of foreign language acquisition (Ellis, 1994). Blended teaching and learning made the students' writing motivation obviously aroused, especially the abilities of the information search and collection, vocabulary accumulation, as well as the writing interest, confidence and sense of achievement, were greatly enhanced.

\section{CONCLUSION}

From the above discussion and analysis, it can be concluded that blended learning can be significantly beneficial to Chniese students as it will improve learning quality, and it will stimulate learning and provide more collaborative learning experiences, It is easier for the students to increase their access to the writing information. Blended learning has a great effect on improving students' information literacy and critical thinking. As the students can accept new technology rapidly and learn easily to handle it, it is time that we instructors adjust to such great change in order to catch up with the growing demands for the students.

\section{REFERENCES}

[1] Driscoll, M. (2002) Blended Learning: let's get beyond the hype, Elearning, 1 March. Available at: http://elearningmag.com/ltimagazine

[2] Singh, H. (2003). Building effective blended learning programs Educational Technology, 43, pp. 51-54

[3] Jigang, Cai. A comparative study of online peer feedback and teacher feedback in Chinese college students' English writing. Foreign Language World, Shanghai, 2011, 2, pp. 65-72

[4] Chunyan, Shao. The multi-role participation model of English Majors" writing teaching from the perspective of social culture. Foreign language world, shanghai, 2016, 2, pp. 79-87

[5] Guohua, Wang. Domestic blended learning research status analysis China Distance Education, Beijing, 2015, 2, pp. 25-31

[6] Kekang, He. The development of education technology from blended learning, E-education Research, Lanzhou, 2004, 7, pp. 8-9

[7] Vygotsky, 1. Interaction between learning and development. Readings on the Develooment of Children. 1978, 23 (3). pp. 34-41

[8] Ellis R.The Study of Language Acquisition, Oxford: OUP,1994 